\title{
Crystal Structure and Rietveld Refinement of Zeolite A SYNTHESIZED FROM FINE-GRAINED PERLITE WASTE MATERIALS
}

\author{
V. Psycharis ${ }^{1}$, V. Perdikatsis ${ }^{2}$ and G. Christidis ${ }^{2}$ \\ 1 Institute of Materials Science, NCSR Dimokritos, 15310 Ag. Paraskevi, Athens, Greece, \\ vpsychar@ims.demokritos. \\ ${ }^{2}$ Technical University of Crete, Department of Mineral Resources Engineering, 73100 Chania, \\ Greece vperdik@mred.tuc.gr, christid@mred.tuc.gr
}

\begin{abstract}
Synthetic zeolites have been produced from a variety of natural silica-rich rocks including volcanic glasses, such as perlite and pumice. The Zeolite studied in this work has been synthesized from perlite and expanded perlite fines. Detailed powder $X$-ray diffraction studies determined it as Zeolite A. In early studies the structure of Zeolite-A was described with a cubic cell with $a=12.3 \AA$ and space group Pm-3m. However the observation of the (531) reflection indicates that a F lattice with a larger cell of $24.60 \AA$ gives a more accurate description. Two end products were studied on the basis of the degree of crystallization of the parent gels to zeolite A. One end product was characterized by total conversion of the incipient gel to zeolite A with high degree of crystallinity, whereas in the second a substantial amount of the original gel did not crystallize out and zeolite $A$ coexisted with amorphous material. The former resulted from gels with $\mathrm{SiO}_{2} / \mathrm{Al}_{2} \mathrm{O}_{3}$ molar ratio $2: 1$ and 5 hours reaction time and the latter from gels with $\mathrm{SiO}_{2} / \mathrm{Al}_{2} \mathrm{O}_{3}$ molar ratio of $2.5: 1$ and 3 hours reaction time. The $\mathrm{X}$-ray powder diffraction data recorded from the former sample were used for the analysis of the crystal structure of zeolite $A$ and the final model was refined by the Rietveld method.
\end{abstract}

\section{INTRODUCTION}

Zeolites have been utilized successfully by the chemical industry and in environmental protection, because of their physical and chemical properties, which include molecular sieving, adsorbing and cation exchange capacity. Synthetic zeolites have been produced from a variety of natural silica-rich rocks including volcanic glasses, such as perlite and pumice. Zeolite $A$ was first synthesized in commercial quantities by Linde Co in 1956 (Breck, 1974). Giordano et al. (1987) proposed the formation of high added value zeolite A from pumice. Christidis et al. (2002) synthesized zeolite A from perlite and expanded perlite fines. The zeolite A produced from this work was utilized in the present study.

\section{EXPERIMENTAL}

\subsection{Synthesis}

Details for the synthesis are given by Christidis et al. (2002). The synthesis of the studied material was carried out in two steps. In the first step the perlite, which consisted principally of volcanic glass $(>95 \%)$, quartz, acidic plagioclase and biotite, and had a $\mathrm{SiO}_{2} / \mathrm{Al}_{2} \mathrm{O}_{3}$ molar ratio 9.12 , was treated with $\mathrm{NaOH}$ in an inconel autoclave (Parr Instruments) at $120^{\circ} \mathrm{C}$ for 2 hours. The resulting liquid was polymerized using various amounts of sodium aluminate producing gels with $\mathrm{SiO}_{2}: \mathrm{Al}_{2} \mathrm{O}_{3}$ molar ratios ranging between $1.75: 1$ and $2.5: 1$. The gels aged under continuous stirring for 16 hours at room temperature. The synthesis of zeolite $A$ was carried out at $95 \pm 2^{\circ} \mathrm{C}$ without stirring. Two end products were selected for detailed study of their crystal structure on the basis of the degree of crystallization of the parent gels to zeolite A. 


\subsection{X-ray diffraction}

X-ray powder diffraction data were collected with a D500 SIEMENS diffractometer employing CuKa radiation and a secondary beam graphite monochromator. The measured 2 theta range (20$90^{\circ}$ ) was scanned in steps of $0.03^{\circ}$ with a counting time of $6 \mathrm{~s} / \mathrm{step}$. This 2 theta range was used for the Rietveld refinement. The aperture and the soller slits were set at $1.0^{\circ}$.

\section{RESULTS AND DISCUSSION}

In figure 1 , the phase diagram for different $\mathrm{SiO}_{2} / \mathrm{Al}_{2} \mathrm{O}_{3}$ molar ratios in the starting gels are shown. According to this, in the end product studied the Zeolite A phase dominates because the $\mathrm{SiO}_{2}: \mathrm{Al}_{2} \mathrm{O}_{3}$ molar ratio in the starting gels was less than 3 . For gels with $\mathrm{SiO}_{2} / \mathrm{Al}_{2} \mathrm{O}_{3}$ ratios greater

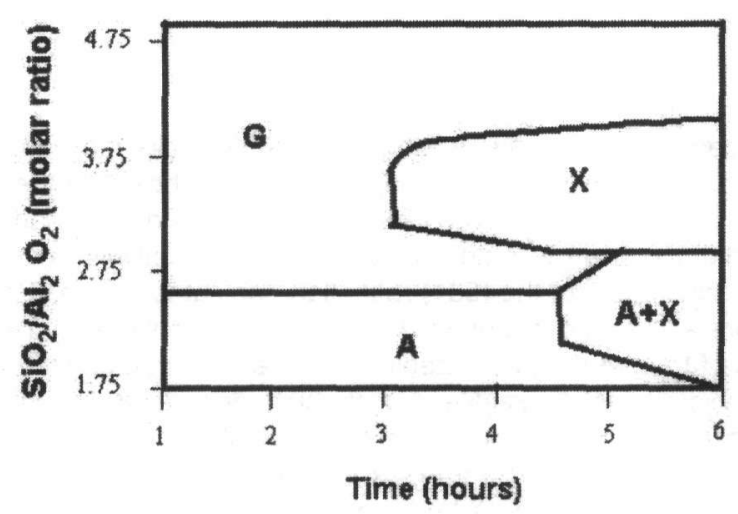

Figure-1. Phase diagram as a function of time for the different Si/Al molar ratios

than 3:1 (or Si/Al >1.5) the end products contain the Zeolite $\mathrm{X}$ phase plus a glass phase (as indicated by $G$ in figure 1). These results are consistent with the dependence, of the crystalline form of the Zeolite produced, on the Si /AI molar ratio. Zeolite-A, Zeolite-X and Zeolite-Y belong to the same family of Zeolites concerning the crystallographic units needed to build their structures (Smart \& Moore 1992). In figure 2 the framework structures of these three types of Zeolites are shown. The basic building polyhedron is the truncated octahedron (Fig. 2 a) which according to Fedorov is one of the five space filling polyhedra (Smith 1982). The corners of this polyhedron are occupied by $\mathrm{Al}$ or $\mathrm{Si}$ atoms and the middle of the edges by an oxygen atom. So, the primary building units of all these structures are $\left[\mathrm{AlO}_{4}\right]^{5-}$ or $\left[\mathrm{SiO}_{4}\right]^{4-}$ tetrahedra. The $\mathrm{Si}$ or $\mathrm{Al}$ tetrahedra are linked by corner sharing and form the four and six edge faces of the truncated octahedron (Fig. $2 \mathrm{~b}$ ). The trunkated octahedron is also known as $\beta$-cage or sodalite unit, because by joining together these polyhedra through the four edge faces the framework of mineral sodalide is formed (Fig. $2 \mathrm{c}$ ). Because of the space filling property, the cavity formed by eight neighboring sodalite units that shares four edge faces, is itself a sodalite unit (Fig. 2 c). The framework of synthetic Zeolite-A is formed by joining the corners of the four edge faces of sodalite units through oxygen atom bridges (Fig, 2d). By linking the sodalite units in this way a cavity is formed which is an Archimedean solid called great rhombicuboctahedron and also known as $\alpha$-cage (Fig. $2 \mathrm{e}$ ). The sieving properties of Zeolite-A results from the 8-oxygen rings, which have a net opening of $4.1 \AA$. Loewenstein (1942) has shown that two aluminum atom ions cannot share the same oxygen ion and retain a cordination of 4. A consequence of this principle is the fact that these frameworks are build by alternately joining aluminium and silicon tetrahedra. In sodalite mineral and in synthetic Zeolite-A the value of $\mathrm{Si} / \mathrm{Al}$ atom ratio is close to one or a little higher. For values of Si/Al atom ratio in the range 1 to 1.5 the Zeolite-X phase is formed and for values in the range 1.5 to 3 the Zeolite-Y is synthesized. The framework of these two zeolites is shown in figure- $2 \mathrm{f}$ and it is created by linking the hexagonal faces with oxygen atom bridges. Frameworks of the types presented above and constructed solely from $\left[\mathrm{SiO}_{4}\right]^{4-}$ tetrhedra would be neutral. The substitution of $\mathrm{Si}^{+4}$ with $\mathrm{Al}^{+3}$ in the frameworks de- 
scribed above creates an electrical imbalance and the overall neutrality of the structure is preserved by the inclusion at interstitial sites of cations $M$.

a)

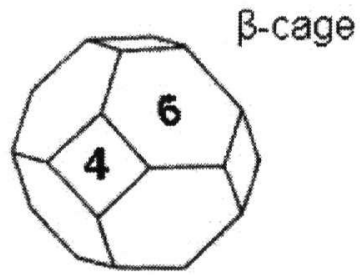

c)

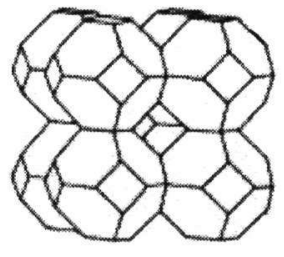

e)

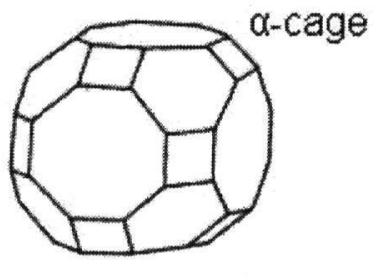

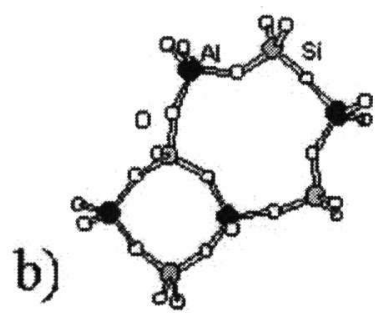

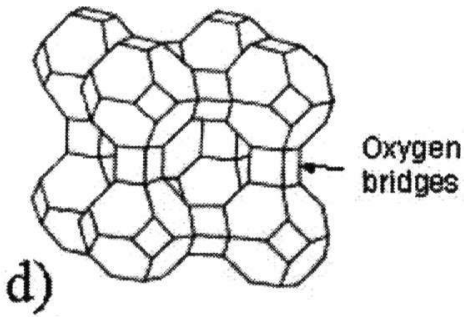

Oxygen bridges

Figure-2 Building blocks for Zeolite-A, Zeolite-X and Zeolite-Y.

The studied sample was synthesized from a gel with $\mathrm{SiO}_{2} / \mathrm{Al}_{2} \mathrm{O}_{3}$ molar ratio $2: 1$ (or $\mathrm{Si} / \mathrm{Al}$ atom ratio 1) and 5 hours reaction time. A part of the XRD pattern from this sample is given In figure 3. Based on the properties (Breck et al. 1956) and on X-ray powder diffraction data from a new synthesized Zeolite Reed \& Breck (1956) suggested the first structural model for the so called ZeoliteA, since then. In this first model the crystal system is considered as cubic, the structure is described in Pm-3m space group and the unit cell edge is $12.29 \mathrm{~A}$. Using this cell, almost all the reflections of the recorded XRD spectra could be indexed (first-row of Miller Indices in figure-3). The theoretical stoichiometric formula for the unit cell content of Sodium Zeolite-A is $\mathrm{Na}_{12} \mathrm{Si}_{12} \mathrm{Al}_{12} \mathrm{O}_{48} \cdot 27.5 \mathrm{H}_{2} \mathrm{O}$ (Reed \& Breck 1956). Based on the argument of Loewenstein (1942) mentioned earlier, that two aluminum atom ions cannot share the same oxygen, Reed \& Breck (1956) suggested that , the Si/Al ratio must be equal or greater to 1 and in this case the structure of Zeolite-A consists of alternating tetrahedra and a cell with $a=24.6 \AA$ is needed in order to describe more accurately the structure. In a subsequent work, Howell (1960) confirms the structural model given by Reed \& Breck (1956), but in addition he gives the first experimental evidence that the true cell has a double a-axis. In the analysed XRD spectra of his sample, a reflection with half integer indices $(5 / 2,1 / 2,3 / 2)$ considering the $a=12.3$ cell has been observed. The indices for this reflection become integers if the cell with $a=24.6$ is used. In the XRD spectrum of the sample studied in 
the present work this reflection is observed and consequently (Fig. 3) the correct cell in order to describe the structure is the one with the double a-axis.

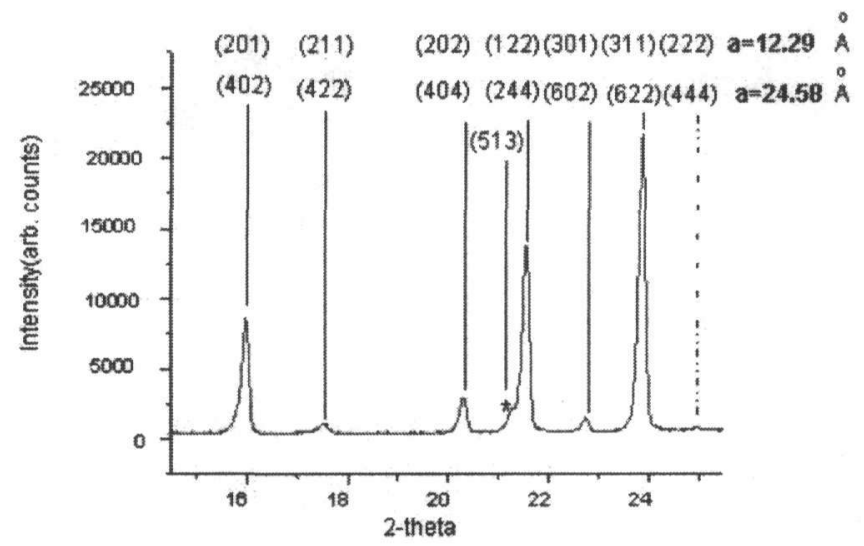

Figure 3. Indexing of the Bragg reflections for Zeolite-A sample based on the cubic pseudocell with a=12.29 $\mathrm{A}$ (S.G. Pm-3m) and on the correct F-centered cell with $a=24.58$ A (S.G. Fm-3c).

The $x$-ray spectrum was analyzed by the Rietveld method and for this purpose the program Fullprof was used ( Rodriquez-Carvajal et al. 1991). The final values for the structural parameters for all atoms obtained by performing a constrained refinement to the positions of the framework atoms (as will be explained latter) are listed in Table-1. At a first step the Fullprof program was run in the Full Pattern Decomposition mode in order to obtain good starting values for the unit cell axis-a and also for the parameters describing the intensity distribution functions. The function used was the split pseudo Voight. With the extracted values of the observed structure factors |Fobs| it was easy to lo

Table 1. Structural parameters for Zeolite-A. Space group No. $226 \mathrm{~F} \mathrm{~m}-3 \mathrm{c}$, unit cell dimensions: $a=24.5659 \mathrm{~A}$ $V=14825.0(2) \AA^{3}$.

\begin{tabular}{lrrrrrrr}
\hline Atom & site & $\mathbf{x}$ & $\mathbf{y}$ & $\mathbf{z}$ & $\mathbf{B}\left(\AA^{2}\right)$ & Occ. & Atoms in the Unit Cell \\
\hline $\mathrm{Si}$ & $96 \mathrm{i}$ & 0 & $0.0926(2)$ & $0.1835(2)$ & $1.87(5)$ & 1.0 & 96 \\
$\mathrm{Al}$ & $96 \mathrm{i}$ & 0 & $0.1862(2)$ & $0.0905(2)$ & $1.87(5)$ & 1.0 & 96 \\
$\mathrm{O}(1)$ & $96 \mathrm{i}$ & 0 & $0.1089(3)$ & $0.2471(4)$ & $2.81(9)$ & 1.0 & 96 \\
$\mathrm{O}(2)$ & $96 \mathrm{i}$ & 0 & $0.1459(4)$ & $0.1482(4)$ & $2.81(9)$ & 1.0 & 96 \\
$\mathrm{O}(3)$ & $192 \mathrm{j}$ & $0.0526(3)$ & $0.0579(2)$ & $0.1730(2)$ & $2.81(9)$ & 1.0 & 192 \\
& & & & & & & \\
$\mathrm{Na}(1)$ & $64 \mathrm{~g}$ & $0.1058(2)$ & $0.1058(2)$ & $0.1058(2)$ & $7.1(2)$ & $0.94(1)$ & $60.2(6)$ \\
$\mathrm{Na}(2)$ & $192 \mathrm{j}$ & $0.0327(9)$ & $0.2246(7)$ & $0.2246(7)$ & $7.1(2)$ & $0.13(1)$ & $25(2)$ \\
$\mathrm{Ow}(1)$ & $64 \mathrm{~g}$ & $0.062(1)$ & $0.062(1)$ & $0.062(1)$ & $7.1(2)$ & $0.21(1)$ & $13.4(6)$ \\
$\mathrm{Ow}(2)$ & $64 \mathrm{~g}$ & $0.1528(5)$ & $0.1528(5)$ & $0.1528(5)$ & $7.1(2)$ & $0.56(1)$ & $35.8(6)$ \\
$\mathrm{Ow}(3)$ & $192 \mathrm{j}$ & $0.1117(5)$ & $0.1557(7)$ & $0.2718(7)$ & $7.1(2)$ & $0.35(1)$ & $67(2)$ \\
$\mathrm{Ow}(4)$ & $8 \mathrm{a}$ & 0.25 & 0.25 & 0.25 & $7.1(2)$ & $0.58(1)$ & $4.6(1)$ \\
\hline
\end{tabular}

cate the positions of the framework atoms, $\mathrm{Al}, \mathrm{Si}, \mathrm{O}(1), \mathrm{O}(2)$ and $\mathrm{O}(3)$ by applying the direct methods of SHLEX-86 program (Sheldrick 1986). For the part of the work that is related to the analysis of |Fobs| in order to locate the position of atoms in the crystal structure of the studied sample, the program suite WINGX was used (Farrugia 1999). A Rietveld refinement was performed by using only the positions of the framework atoms (AI, Si, O(1), O(2) and $\mathrm{O}(3)$ ). The high values of the agreement factors $\left(R_{p}=26.3 \%, R w p=43.7 \%\right.$ and $\left.R_{B}=47.4 \%\right)$ indicate that the structural model is 


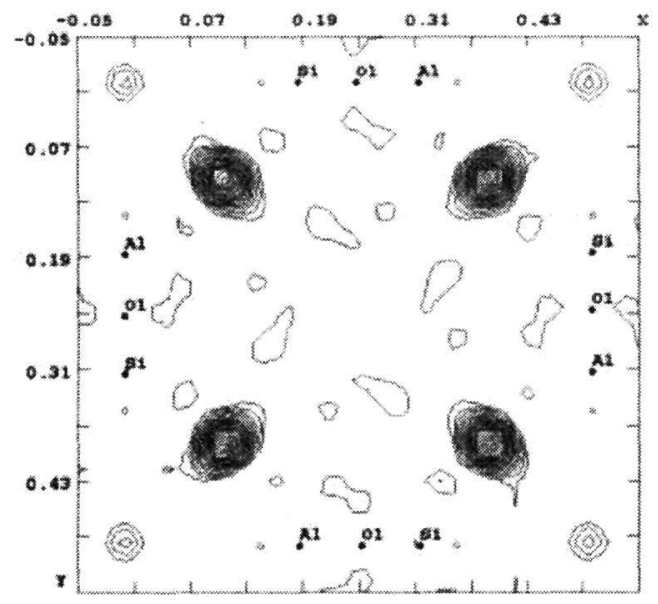

a)

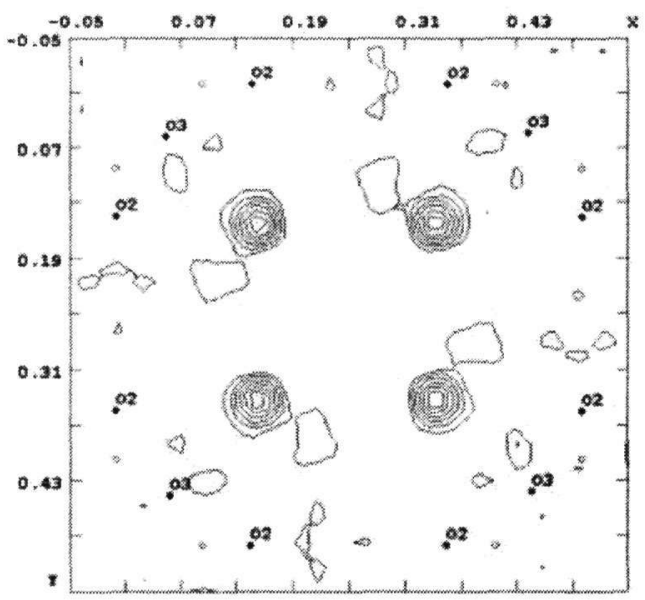

b)

Figure 4. $X Y$ sections of Difference Fourier maps at $z=0.10$ (a) and $z=0.16$ levels

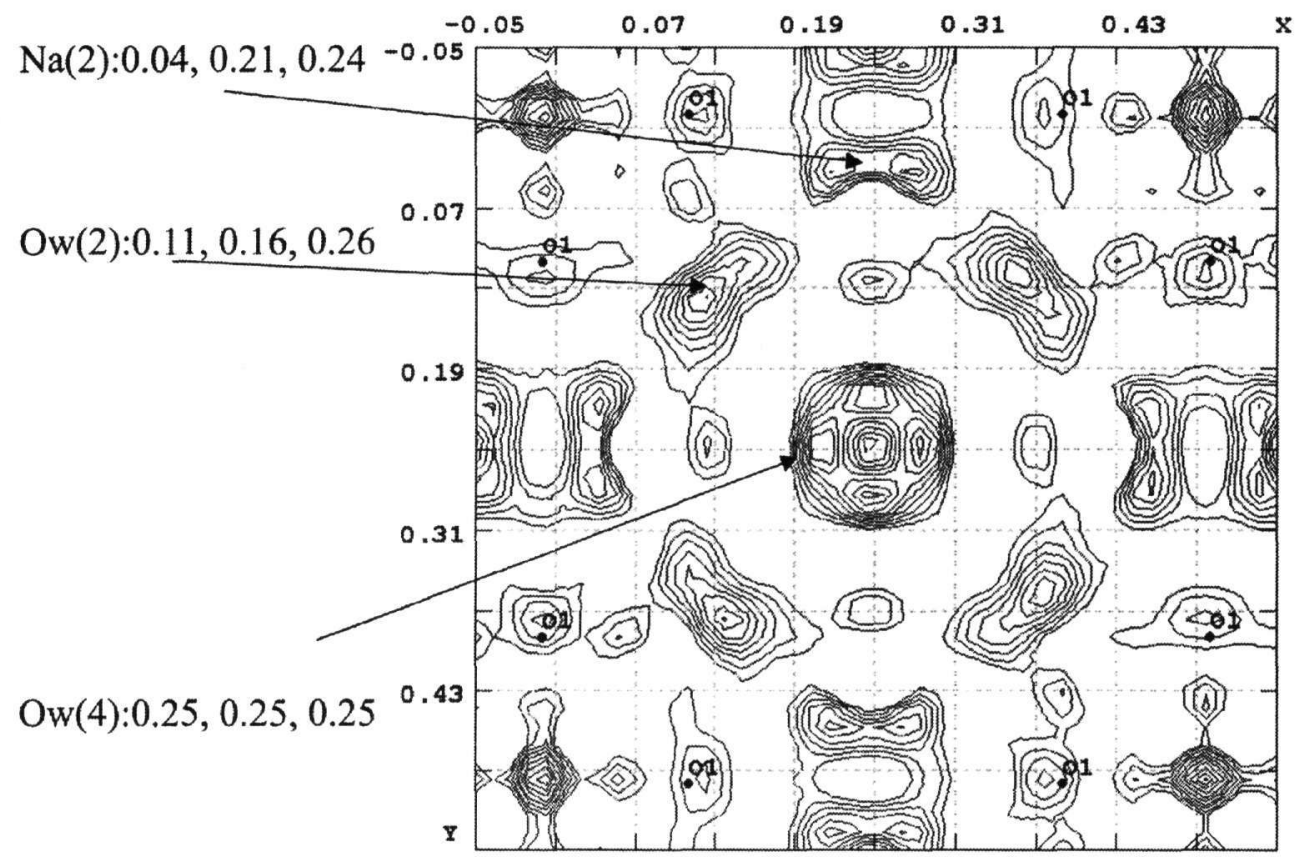

Figure 5. XY section of Difference Fourier maps at $z=0.25$

incomplete. The diffraction peaks in a powder diffraction pattern are overlapped and so with a correct but incomplete model more accurate |Fobs| values are obtained by the Rietveld deconvolution method (Rietveld 1969). The new |Fobs| values calculated at the end of this stage of Rietveld refinement, were used for the calculations of difference Fourier maps. The $X Y$ sections of the maps at $z=0.10$ and $z=0.16$ are shown in figure $4 a$ and $4 b$ correspondingly.

Taking into account the previous studies the site $(x, y, z)=(0.10,0.10,0.10)$ it was considered as the $\mathrm{Na}(1)$ atom site and the one at $(x, y, z)=(0.16,0.16,0.16)$ as the site of an oxygen atom belonging to 
a water molecule. These two atoms were added in the starting model and a new Rietveld refinement was performed. The agreement factors were convergent to lower values $R_{p}=18.4 \%$, $R_{\mathrm{wp}}=26.1 \%, \mathrm{R}_{\mathrm{B}}=32.1 \%$ but they are still high, indicating that these atoms are part of the structure and in addition that there are more atoms not located yet. The difference Fourier map calculated at the end of the refinement is given in figure 5 . Three additional atoms sites were located, the $\mathrm{Na}(2)$, $\mathrm{Ow}(2)$ and $\mathrm{Ow}(4)$. Including these new atoms in the structural model and performing Rietveld refinement, the agreement factors take the values $R_{p}=8.14 \%, R_{w p}=10.6 \%, R_{B}=11.7 \%$. From the other observed peaks in the new Fourier Map only the one at the site: $(x, y, z)=(0.06,0.06,0.06)$ [oxygen atom of water molecule $\mathrm{Ow}(1)$ ] was survived during the final refinement . The final refinement gave values of the agreement factors : $R_{p}=7.1 \%, R_{w p}=9.1 \%, R_{B}=7.8 \%$. The Rietveld refinement diagrams are presented in figure 6.

In order to get a reasonable structural model for the part of the structure formed by the framework atoms, restrains were applied to the angles and bonds for both $\mathrm{Si}$ and $\mathrm{Al}$ tetrahedra. The angles were constrained to $110.0^{\circ}$ with a standard deviation of $0.1^{\circ}$, and the bonds distances of $\mathrm{Si}_{\text {, }}$ $\mathrm{O}$ atoms were constraint to $1.59 \AA$ with standard error $0.02 \mathrm{~A}$ and those of $\mathrm{Al}, \mathrm{O}$ atoms were constraint to $1.71 \AA$ with standard error $0.02 \mathrm{~A}$.

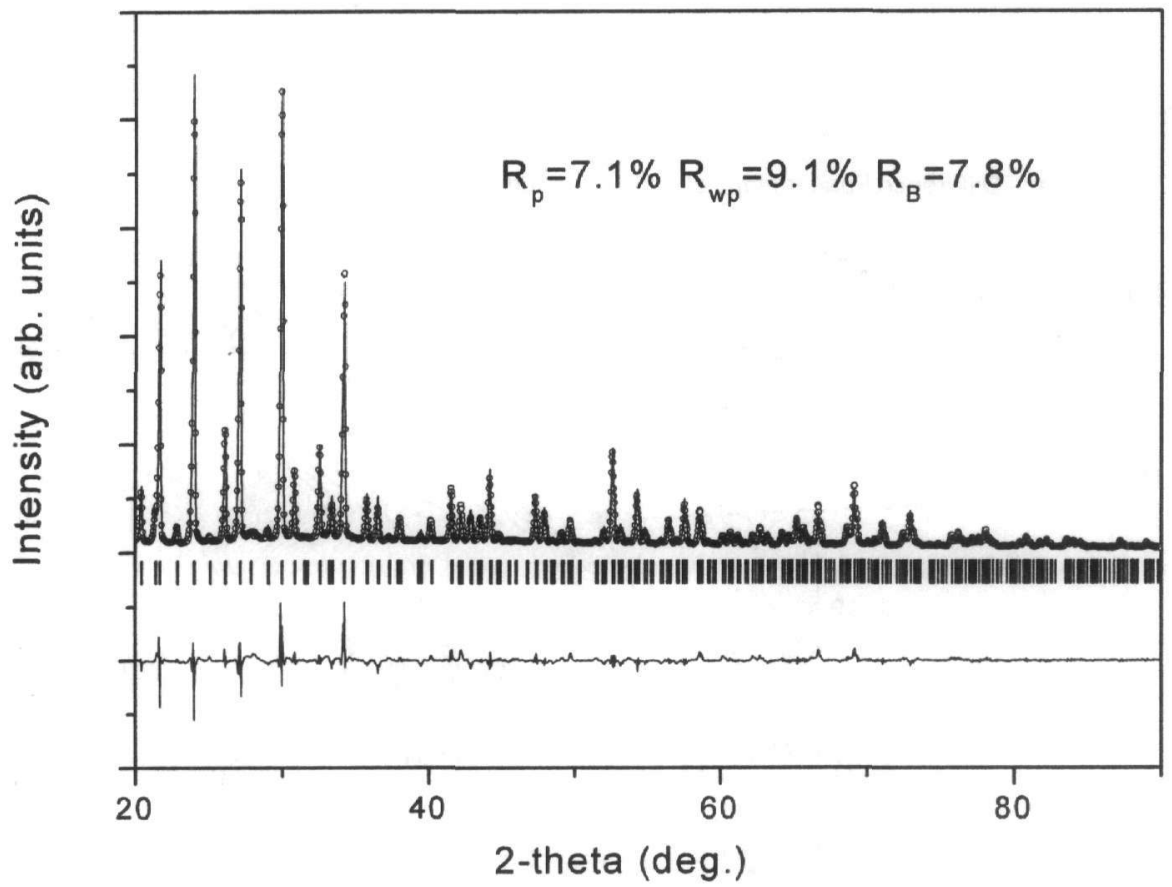

Figure 6. XRD spectrum of Zeolite A refined by the Rietveld method. The continuous line corresponds to the calculated spectrum, vertical bars (D) indicate the position of Bragg peaks. The bottom trace depicts the difference between the experimental and the calculated intensity values

The $\mathrm{Na}(1)$ atoms are located in the middle of 6-oxygen rings ( $\beta$-cage) (Fig.-7) and are almost fully $(94 \%$ sea Table-1) occupied as is usually the case in hydrated and dehydrated Zeolite-A compounds (Gramlich \& Meier 1971, Pluth \& Smith 1980, Ikeda et al. 1998). The $\mathrm{Na(2)}$ atom sites are statistically occupied by sodium atoms located around the centre of the 8-oxygen ring (a-cage) (Fig.-7). The occupancy factor for $\mathrm{Na}(2)$ sites takes the same value as in the study Pluth \& Smith 1980 , Ikeda et al. 1998, but is less (almost 1/3) than the corresponding value in the study of Gramlich \& Meier 1971. $\mathrm{Na}(1), \mathrm{Na}(2)$ atoms are clearly located within the a-cage (Fig.-7). In the analysis of our data no indication for occupation of the $\mathrm{Na}(3)$ sites $(0.25,0.10,10)$ is given, as has been observed in the studies of Pluth \& Smith 1980 and Ikeda et al. 1998. 


\section{$\mathrm{Na}(2) \mathrm{Na}(1)$ Al Si $\mathrm{O}$ Ow(2) Ow(3) \\ $\theta$ 曲 $\bigcirc 00$ (1)}

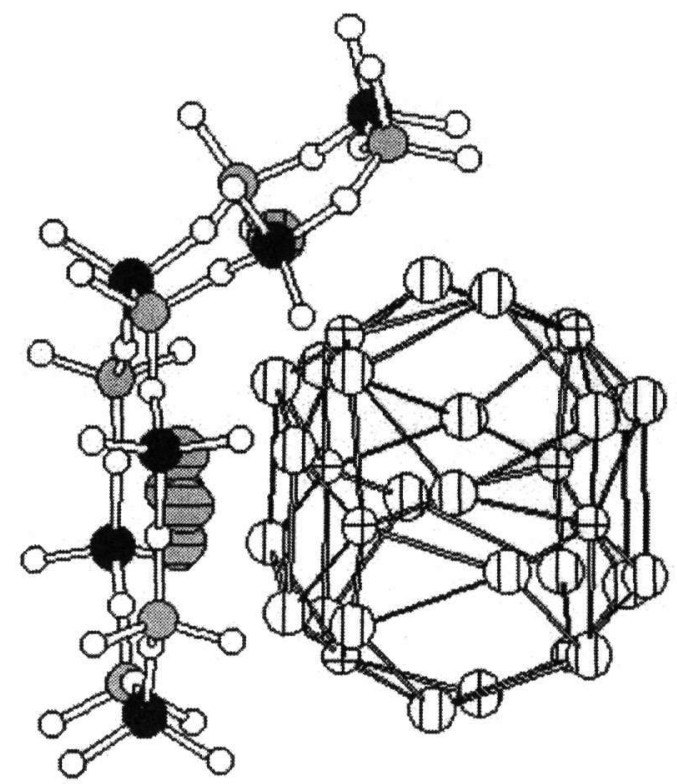

Figure 7. Cluster formed by the oxygen atoms of water molecules within the a-cage. The positions of $\mathrm{Na}(1)$ and $\mathrm{Na}(2)$ atoms are also shown. The $\mathrm{Na}(2)$ atoms are located within the 8-oxygen atom rings of the great rhombicuboctahedron.

The sites $O w(2)$ and $O w(3)$ (cross and vertically hatched circles correspondingly in figure 7) are occupied by oxygen atoms belonging to water molecules that lie within the large $a$-cages and are at the sites (II, III) mentioned in the paper of Gramlich \& Meier (1971). These sites have also identified as water oxygen atom sites in Ikeda et al. 1998. The sites O(4) at the centre of the large a-cage have also been located in agreement with previous studies.

Within its a- and $\beta$-cage there are: $\sim 11 \mathrm{Na}$ atoms ( 8 at $\mathrm{Na}(1)$ and 3 at $\mathrm{Na}(2)$ sites) and $13.8 \mathrm{OW}$ atoms $(\sim 4.5$ at $\mathrm{Ow}(2), \quad 8.7$ at $\mathrm{Ow}(3)$ and 0.6 at $\mathrm{Ow}(4)$ sites. Aproximately half than those (23) given by Gramlich \& Meier 1971. Theoretical studies have shown that the location and occupation of the cation sites are highly correlated with the location and occupation of the water molecule sites (Higgins et al. 2002).

Inside the $\beta$-cage (Fig. 8) the only site which gave a stable refinement was that of Ow(1). This is very close to sites given in the past for water. The water molecules that occupy sites within the $\beta$ - cage are the most stable and according to theoretical ( Higgins et al. 2002) and experimental studies (Pissis et al. 1993 ) they are occupied even in dehydreted A-Zeolites. The number of the water molecules calculated in the present study to lie within the $\beta$-cage are approximately 3.5 . 


\section{$\mathrm{Na}(1)$ Al Si o Ow(1)

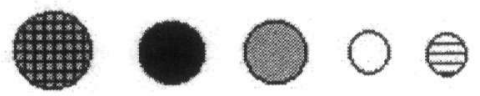

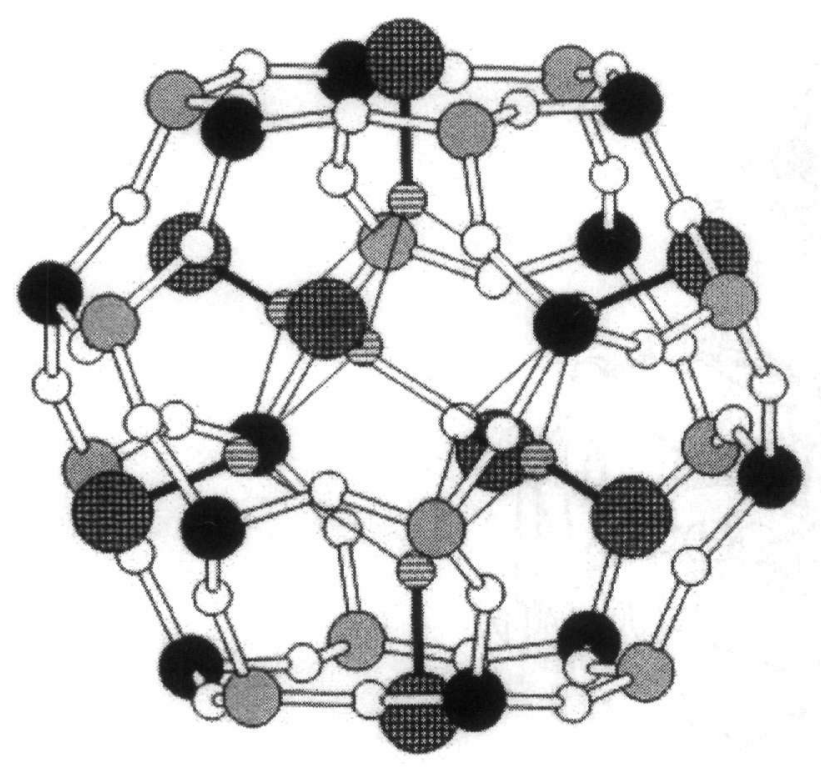

Figure 8 . The small $\beta$-cage (sodalite unit) and the cluster formed by the oxygen atoms occupying the Ow(1) sites. The sites of $\mathrm{Na}(1)$ atoms are shown.

Taking into account the values for the occupancy factors given in Table-1 the calculated formula unit is $\mathrm{Na}_{10.6(3)} \mathrm{Si}_{12} \mathrm{Al}_{12} \mathrm{O}_{48} \cdot 15.4(4) \times \mathrm{H}_{2} \mathrm{O}$. This results in Zeolite-A with low water molecule content. According to Reed and Breck (1956) the water content $(=N)$ ranges from 20 to 30 per formula unit. The location of water molecules within the cages is a difficult task even with X-ray data from single crystals. In the work of Gramlich and Meier (1971) all the disordered atoms, including the sodium atoms, are refined as oxygen atoms and so they do not give a stoicheiometric formula unit as a result of their analysis. An interesting discussion for the water molecules contained in the cages of Zeolite-A, is contained in Ikeda et al. (1998). In this work the calculated number of water molecules is 31.86 per stoicheiometric formula unit. A value very close to the highest one (30 According to Reed and Breck (1956)) and close to that obtained by thermidometry (31 water molecules per formula unit) in the same work. As the authors mention at the end of the conclusions, with their specific method of analysis of $\mathrm{X}$-ray diffraction data it was possible to locate water molecules at sites never observed before. Another result that is in agreement with the low water molecule is the unit cell constant, which is $24.5659 \AA$. This value is closer to the cell dimension of the dehydrated Zeolite-A. The values calculated by lkeda et al. (1998) are 24.5335 A for $N \sim 1,24.5693$ $\AA$ for $N \sim 5.5$ and $24.6077 \AA$ for the hydrated one with $N=31.86$. Pluth and Smith (1980) give $\mathrm{a}=24.555 \AA$ for a dehydrated Zeolite-A.

According to Smart \& Moore (1992) the molecular sieve property of Zeolite-A, is based on the window of the 8-oxygen atom ring, which has a free diameter of $4.1 \AA$ (as defined in Meier \& Olson (1987)) and form channels along the $a, b, c$ crystal axes. The 6-oxygen atom rings are always occupied by sodium atoms ( $\mathrm{Na}(1)$ sites) and these sites are important for cation exchange property of Zeolite-A. 


\section{CONCLUSIONS}

The crystal structure of zeolite A, synthesized from perlite and expanded perlite fines was solved up initio by applying the direct methods and refined by Rietveld refinement techniques. Due to $(513$ ) reflection the true cell with $a=24.60 \AA$ in S.G. Fm-3c was chosen.

Two different positions for the $\mathrm{Na}$ atoms are located. The $\mathrm{Na}(1)$ atoms are located in the middle of 6 -oxygen rings ( $\beta$-cage) and are almost fully (94\%) occupied as is usually the case in hydrated and dehydrated Zeolite-A compounds. The $\mathrm{Na}(2)$ atom sites are statistically occupied by sodium atoms located around the centre of the 8-oxygen ring (a-cage). The occupancy factor for $\mathrm{Na}(2)$ sites takes the same value as in the study Pluth \& Smith 1980, Ikeda et al. 1998, but is less (almost 1/3) than the corresponding value in the study of Gramlich \& Meier 1971. $\mathrm{Na}(1), \mathrm{Na}(2)$ atoms are clearly located within the $\alpha$-cage. In the analysis of our data no indication for occupation of the $\mathrm{Na}(3)$ sites $(0.25,0.10,10)$ is given, as has been observed in the studies of Pluth \& Smith 1980 and Ikeda et al. 1998. Taking into account the values for the occupancy factors, the calculated formula unit is $\mathrm{Na}_{10.6(3)} \mathrm{Si}_{12} \mathrm{Al}_{12} \mathrm{O}_{48} \cdot 15.4(4) \mathrm{H}_{2} \mathrm{O}$ a result that corresponds to a hydrated Zeolite-A with a low water content.

\section{REFERENCES}

Breck D. W., Eversole W. G., Milton R. M.,. Reed T. B and Thomas T. L. (1956) Crystalline Zeolites. I. The Properties of a New Synthetic Zeolite, Type A. J. Am. Chem. Soc. 78, 5963

Breck, D.W. (1974) Zeolite Molecular Sieves; John Wiley: New York.

Giordano, N., Recupero, V., Pino, L., \& Bart, J.C.J. (1987) Zeolitization of perlite. A prospective route. Ind. Miner. September 1987, 83-95.

Christidis G.E., Galani, K. and Markopoulos T. (2002) Synthesis of high added value zeolites from perlite and expanded perlite waste materials. In: Industrial Minerals and Extractive Industry Geology (PW. Scott \& C.M. Bristow eds), Geol Soc Publ. House, 345-350

Farrugia L. J. (1999). WinGX suite for small-molecule single-crystal crystallography J. Appl. Cryst. 32, 837-838

Gramlich V. and Meier W. M. (1971) The crystal structure of hydrated NaA: A detailed refinement of a pseudosymmetric zeolite structure. Z. Kristallogr. 133, 134-139

Higgins F. M., de Leeuw N. H. and Parker S. C. (2002) Modelling the effect of water on cation exchenge in Zeolite A. J. Mater. Chem. 12, 124-131

Ikeda T., Izumi F., Kodaira T., and Kamiyama T. (1998) Structural Study of Sodium-Type Zeolite LTA by Combination of Rietveld and Maximum-Entropy Methods. Chem. Matter. 10, 3996-4004

Meier W. M. and Olson D. H. (1987) Atlas of Zeolite Structure Types. Second revised edition, pages 86-87, by Butterworths, London.

Howell P. A. (1960) A refinement of the cation positions in synthetic Zeolite Type A, Acta Cryst. 67, 737

Loewenstein W (1942) The distribution of aluminum in the tetrahedra of silicates and aluminates Am. Mineralogist, 39,92

Pissis P. and Daoukaki-Diamanti D. (1993) Dielectric Studies of molecular mobility in hydrated zeolites, J. Phys. Chem. Solids 54 (1993) 701

Pluth J. J., Smith J. V. (1980) Accurate Redetermination of Crystal Structure of Dehydrated Zeolite A. Absence of near Zero Coordination of Sodium. Refinement of Si,Al-Ordered Superstructure. J. Am. Chem. Soc. 102, 4704.

Reed, T.B. and Breck, D.W. (1956) Crystalline Zeolite.II. Crystal structure of synthetic zeolite, type A. J. Am. Chem. Soc. 78,5972

Rietveld H. M. (1969) A profile refinement method for nuclear and magnetic structures. J. Appl. Crystallogr. 2, 65

Rodriquez-Carvajal J. M. T. Fernadez-Diaz, and J. L. Martinez, (1991) Neutron diffraction study on structural and magnetic properties of La2NiO4. J. Phys. Condens. Matter 3, 3215.

Sheldrick G.M., SHELXS-86, Structure Solving Program, University of Göttingen, Göttingen, Germany, 1986.

Smart L. and Moore L. (1992), Solid State Chemistry-An introduction, Chapter 5 pages 183-209, by Chapman \& Hall London

Smith J. V. (1982) Geometrical and Structural Crystallography, pages 161-171, by John Wiley \& Sons, Inc New York 